Etude des migrations dans l'Ouest africain (Comité Interafricain pour les Sciences Humaines de la CCT $A / C S A$ ) (voir Africa, xxvi. 4, 1956, pp. 408-9)

CONFORMÉmENT à la Recommandation No. 18 de la Conférence Interafricaine des Sciences Humaines (Bukavu, août-septembre 1955) et après la Réunion de spécialistes sur les migrations qui s'est tenue à Londres du 4 au 8 juillet 1996 au siège du Secrétariat conjoint de la CCTA/CSA, l'étude systématique des migrations dans l'Ouest africain a été mise en route conjointement par des chercheurs britanniques (Gouvernement et Université de la Côte-del'Or) et français (Centre National de la Recherche scientifique, Conseil Supérieur des Recherches sociologiques Outre-Mer, Office de la Recherche scientifique et technique Outre-Mer, Institut Français d'Afrique Noire).

Les contacts pris à Accra par M. Jean-Paul Lebeuf, Secrétaire du Comité Interafricain pour les Sciences Humaines, et la présence de M. Jean Rouch sur le terrain depuis novembre 1956 ont permis que soient coordonnés les différents programmes prévus dont l'application a d'ores et déjà commencé. Parallèlement aux enquêtes entreprises aux points de départ des migrations (Côte d'Ivoire et Haute-Volta, principalement), des recherches sont poursuivies tout au long des routes empruntées par les migrants en Côte-de-l'Or, notamment aux bacs de Yedji et de Bamboî par où passe la majorité d'entre eux.

D'autre part, des enquêtes particulières entreprises dans différentes parties de l'Afrique occidentale ayant montré que les migrations de travailleurs n'avaient pas seulement des causes économiques, des recherches sont entreprises dans les territoires d'origine des migrants et dans ceux où ils s'établissent temporairement, afin de déterminer les diverses motivations qui poussent des centaines de milliers d'individus à se déplacer périodiquement sur des centaines de kilomètres.

\title{
Mission scientifique dans le Nord Cameroun
}

M. Jean-Paud Lebeuf, Chargé de Recherches au Centre National de la Recherche scientifique, a continué ses recherches chez les Fali du Nord-Cameroun (novembre-décembre 1956) à la suite de celles qu'il a entreprises à différentes reprises depuis 1936 chez la même population, et elles font partie d'un programme général d'étude de populations fétichistes du Cameroun septentrional. Elles avaient pour but de coordonner les résultats acquis pendant ces séjours antérieurs, et ont porté principalement sur les structures politique, sociale et familiale, la répartition des villages et des habitations sur le sol, les catégories, la mythologie, les notions d'abstraction et de 'connaissance', en liaison avec une étude générale de l'habitation.

\section{SELECT ANNOTATED BIBLIOGRAPHY OF TROPICAL AFRICA}

A few additional copies of this bibliography are now available

In one volume: 4os. post free

In six separate parts : Ios, each, post free 